\title{
Life cycle and epizootiology of Amblyospora ferocis (Microspora: Amblyosporidae) in the mosquito Psorophora ferox (Diptera: Culicidae)
}

\author{
María V. Micieli ${ }^{1}$, Juan J. García ${ }^{1}$ and James J. Becnel ${ }^{2}$ \\ ${ }^{1}$ Comisión de Investigaciones Científicas Provincia Buenos Aires, Centro de Estudios Parasitológicos y de Vectores, Universidad \\ Nacional de La Plata, Calle 2 No. 584, (1900) La Plata, Argentina; \\ ${ }^{2}$ USDA/ARS, Center for Medical, Agricultural and Veterinary Entomology, P.O. Box 14565, Gainesville, Florida 32604, USA
}

Key words: Microsporidia, Amblyospora ferocis, Culicidae, Psorophora ferox, epizootiology, ultrastructure

\begin{abstract}
A natural population of Psorophora ferox (Humbold, 1820) infected with the microsporidium Amblyospora ferocis García et Becnel, 1994 was sampled weekly during a seven-month survey in Punta Lara, Buenos Aires Province, Argentina. The sequence of development of $A$. ferocis in larvae of $P$. ferox leading to the formation of meiospores followed the developmental pathway previously reported for various species of Amblyospora. The natural prevalence of $A$. ferocis in the larval population of $P$. ferox ranged from $0.4 \%$ to $13.8 \%$. Spores were detected in the ovaries of field-collected females of $P$. ferox and were shown to be responsible for transovarial transmission of $A$. ferocis to the next generation of mosquito larvae in laboratory tests. These spores were binucleate and slightly pyriform in shape. The prevalence of $A$. ferocis in the adult population ranged from $2.7 \%$ to $13.9 \%$. Data on effects of the infection on female fecundity showed that infected field-collected adults of $P$. ferox laid an average of $47.6 \pm 6.5$ eggs of which $35.8 \% \pm 4.1 \%$ hatched. Uninfected field-collected adults of $P$. ferox laid $82.8 \pm 6.8$ eggs of which $64.1 \% \pm 5.5 \%$ hatched. Six species of copepods living together with $P$. ferox were fed meiospores from field-infected larvae but none became infected. Horizontal transmission of $A$. ferocis to $P$. ferox larvae remains unknown.
\end{abstract}

Microsporidia of the genus Amblyospora Hazard et Oldacre, 1975 are common obligate parasites of mosquitoes. These microsporidia are transovarially transmitted via a binucleate spore from infected adult females to their progeny. In these progeny, the microsporidium invades fat body tissue and undergoes a sporulation sequence to produce large numbers of meiospores. These meiospores are not directly infectious to the larval mosquito host but are orally infectious for a copepod intermediate host (Andreadis 1985a, b, Sweeney et al. 1985, Micieli et al. 1998, 2000a, b). Spores formed in the copepod host are infectious per os to the larval mosquito host and initiate a developmental sequence that produces infected adults to complete the cycle.

Several Amblyospora species have been reported infecting mosquitoes from Argentina (García 1989, García and Becnel 1994, Micieli et al. 2000a, b). The life cycles have been elucidated in three of these species (Micieli et al. 1998, 2000a, b). Amblyospora ferocis García et Becnel, 1994 is commonly found infecting Psorophora ferox (Humbold, 1820) in Buenos Aires Province, Argentina. The description of $A$. ferocis was based mainly on the ultrastructure of meiospores from field-infected larvae, and nothing has been reported on the modes of transmission.

During a seven-month study on a natural population of $P$. ferox in Punta Lara, Buenos Aires Province, larvae and adults were found parasitized by $A$. ferocis. This study presents information of pathogen development in larvae and adult female stages of the mosquito host. In addition, field data on prevalence and seasonality of the infection are given.

\section{MATERIALS AND METHODS}

Psorophora ferox is a multivoltine species that develops in temporary pools in the forest. The eggs are resistant to drying and larval development is short, between 5 and 7 days. Females are voracious and aggressively attack man and animals indiscriminately. The species is a vector of Venezuelan encephalitis virus and San Louis encephalitis virus. Psorophora ferox has also been found to carry eggs of Dermatobia hominis (Forattini 1965).

The collection site was a temporary pond $(30 \mathrm{~m} \times 5 \mathrm{~m} \times 0.30$ $\mathrm{m}$ deep) located in a wooded area in Punta Lara (34 51'53"S, $57^{\circ} 52^{\prime} 23^{\prime} \mathrm{W}$ ), Buenos Aires Province, Argentina. The pond was flooded periodically during the year with water from the Rio de La Plata.

The pond was surveyed twice a week from October, 1994 to April, 1995. Mosquito larvae and copepods were collected with a 600-ml dipper and immediately transported to the laboratory for examination. Human biting collections of mosquito adult females were made weekly right at the site. Mosquitoes landing on the host were collected with a battery-powered aspirator. Biting collections were made during the morning. Females were fed on a restrained chicken placed directly into the screened cage. Engorged females were then removed and placed individually in plastic vials lined with paper and a small amount 
of water for oviposition. Females were maintained at a temperature of $25^{\circ} \mathrm{C}$ and constantly supplied with a $10 \%$ sucrose solution. After oviposition, the females were smeared, stained with Giemsa, and examined for the presence of microsporidian spores. Eggs from 25 infected and 25 uninfected females were counted, hatched and larvae reared in separate sibling batches. Larvae were kept in plastic pans with dechlorinated tap water and they were fed on powdered chicken food at $26 \pm 1^{\circ} \mathrm{C}$ under a photoperiod of 12:12 (L:D). Larvae were examined only for patent infections under the dissecting microscope.

Mosquitoes were identified according to Lane (1953) and Darsie and Mitchell (1985). Copepods were identified according to Ringuelet (1958), Dussart (1969) and Reid (1985).

For the ultrastructural studies, pieces of live infected larvae and infected adult were smeared on microscope slides, air dried, fixed in methanol for $3 \mathrm{~min}$ and stained $10 \mathrm{~min}$ with $10 \%$ Giemsa-stain solution buffered at $\mathrm{pH} 7.41$. Other pieces of infected larvae and infected ovaries were fixed in $2.5 \%$ glutaraldehyde buffered in $0.1 \mathrm{M}$ sodium cacodylate containing $\mathrm{CaCl}_{2}$ $(1 \mathrm{mg} / \mathrm{ml})$ and postfixed in $1 \%$ aqueous $\mathrm{OsO}_{4}(\mathrm{w} / \mathrm{v})$. These tissues were dehydrated through a graded ethanol series into acetone, and embedded in Epon-Araldite. Thin-sections were post-stained with methanolic uranyl acetate followed by lead citrate and photographed with a Hitachi H-600 electron microscope at $75 \mathrm{kV}$.

For exposure of copepods, six species were isolated from the breeding site: Acanthocyclops robustus (Sars, 1863), Macrocyclops albidus (Jurine, 1820), Mesocyclops annulatus (Wierzejski, 1892), Mesocyclops longisetus (Thiébaud, 1914), Microcyclops sp. and Paracyclops fimbriatus fimbriatus (Fisher, 1853). Larvae infected with meiospores of $A$. ferocis were used as inoculum for transmission tests. The different species of copepods were separated into group of 25 to 50 adult females in 100 $\mathrm{ml}$ of water. Each group was exposed to meiospores from mosquito larvae at a final concentration of $1 \times 10^{3}$ spores per $\mathrm{ml}$. Control groups were handled in a similar manner but without the addition of meiospores.

\section{RESULTS}

\section{Amblyospora ferocis in adult Psorophora ferox population}

Field studies. The natural prevalence of $A$. ferocis in adult female populations of $P$. ferox ranged from $2.7 \%$ to $13.9 \%$ (Fig. 1). No adults were collected in early spring (October) but more than $10 \%$ of the first generation of adults from the sites were infected. Somewhat lower levels of infection were noted throughout the summer but they peaked again in early autumn (March).

Laboratory studies. Uninfected field-collected adults of $P$. ferox laid an average of $82.8 \pm 6.8$ (SD) eggs of which $64.1 \% \pm 5.5 \%$ hatched $(\mathrm{n}=25)$. Infected fieldcollected adults of $P$. ferox laid an average of $47.6 \pm 6.5$ (SD) eggs of which $35.8 \% \pm 4.1 \%$ hatched $(n=25)$.

Parasite stages. Microscopic examination of the ovaries from infected adult females revealed the presence of binucleate spores (Figs. 2-7). These spores were slightly pyriform in shape and in Giemsa-stained smears

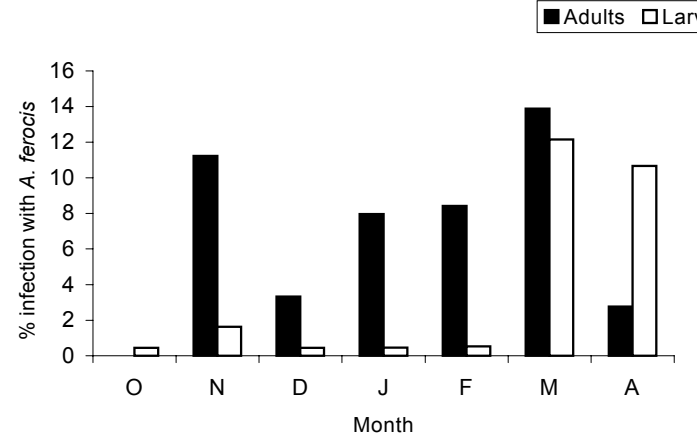

Fig. 1. Prevalence of Amblyospora ferocis in natural populations of Psorophora ferox (adult females and larvae).

were commonly germinated. They measured $5.6 \pm 0.5 \times$ $4.2 \pm 0.6 \mu \mathrm{m}($ fresh, $\mathrm{n}=15)$ and $6 \pm 0.5 \times 3.7 \pm 0.4 \mu \mathrm{m}$ (fixed, $\mathrm{n}=25$ ) (Fig. 2). Ultrastructurally, the spores were characterised by a thin exospore and somewhat thicker endospore and a bipartite and lamellar polaroplast (Figs. 5-7). The polar filament made 5-6 turns in the posterior region of the spore about a large posterior vacuole that was often collapsed probably representing an artifact of processing (Fig. 5). Diplokaryotic vegetative stages were rarely observed and it was not clear whether they represented stages leading to the formation of binucleate spores or sporoplasms from germinated spores. Germinated spores were common (Fig. 2).

Commonly observed feature of infection in adults was an intense host reaction in the form of melanized binucleate spores (Figs. 4a, b). These spores were often germinated as indicated by melanization of the polar tube in some instances (Fig. 4a).

\section{Amblyospora ferocis in larval Psorophora ferox population}

Field studies. The natural prevalence of meiospore infection of $A$. ferocis in larval populations of $P$. ferox ranged from $0.4 \%$ to $13.8 \%$ (Fig. 1). Infection levels were consistently low during the spring and summer months (October-February) but increased greatly in the autumn (March and April).

Parasite development. The sequence leading to the formation of meiospores of $A$. ferocis in larval P. ferox followed the developmental pathway previously reported for various species of Amblyospora. Diplokaryotic meronts multiplied in fat body of transovarially infected progeny. Sporogony was first indicated in diplokaryotic cells by the elaboration of an interfacial envelope and the presence of synaptonemal complexes. A series of 3 divisions followed resulting in an octonucleate sporogonial plasmodium that divided to form 8 sporoblasts. Sporogenesis resulted in the formation of 8 spores within a sporophorous vesicle. Mature spores were typical of Amblyospora and as previously described (García and 


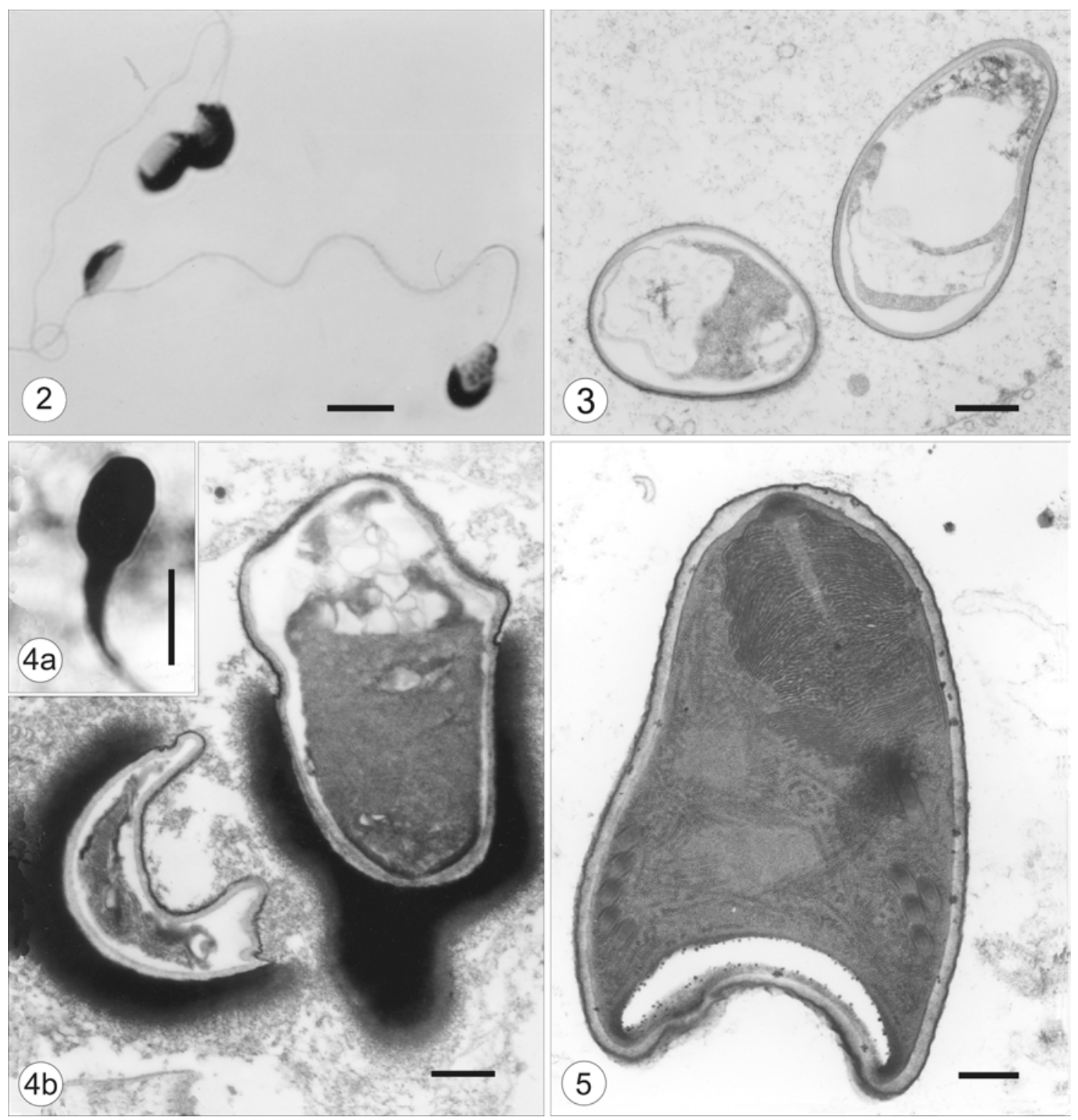

Figs. 2-5. Amblyospora ferocis. Developmental stages in ovaries of adult Psorophora ferox. Fig. 2. Germinated binucleate spores. Giemsa stain. Fig. 3. Transmission electron micrograph (TEM) of germinated spores. Fig. 4a. Melanized spores. Giemsa stain. Fig. 4b. Melanized spores. TEM. Fig. 5. Binucleate spore. TEM. Scale bars: Figs. 2, $4 \mathrm{a}=5 \mu \mathrm{m}$; Figs. 3, $4 \mathrm{~b}=1 \mu \mathrm{m}$; Fig. $5=0.5 \mu \mathrm{m}$.

Becnel 1994). Secretory products were in the form initially as accumulations of massed electron-dense materials that disappeared in the terminal stages of sporogenesis. Tubular materials were also noted late in the sporulation sequence.

Transmission experiments exposing copepods to $\boldsymbol{A}$. ferocis meiospores. None of the six copepod species exposed to meiospores of $A$. ferocis developed any infections by microsporidia. Examinations of fieldcollected copepods also failed to find infected copepods identifiable as Amblyospora.

\section{DISCUSSION}

Previous to this study, Amblyospora ferocis was characterised solely by information on meiospores from the larval stages of the mosquito host Psorophora ferox (García and Becnel 1994). With this study, we have demonstrated binucleate spores in adult $P$. ferox that are responsible for transovarial transmission of $A$. ferocis to larval progeny where meiospore production occurs. The morphology and ultrastructural features of the meiospores are similar to a previous description of $A$. ferocis (García and Becnel 1994). The binucleate spores found in the 


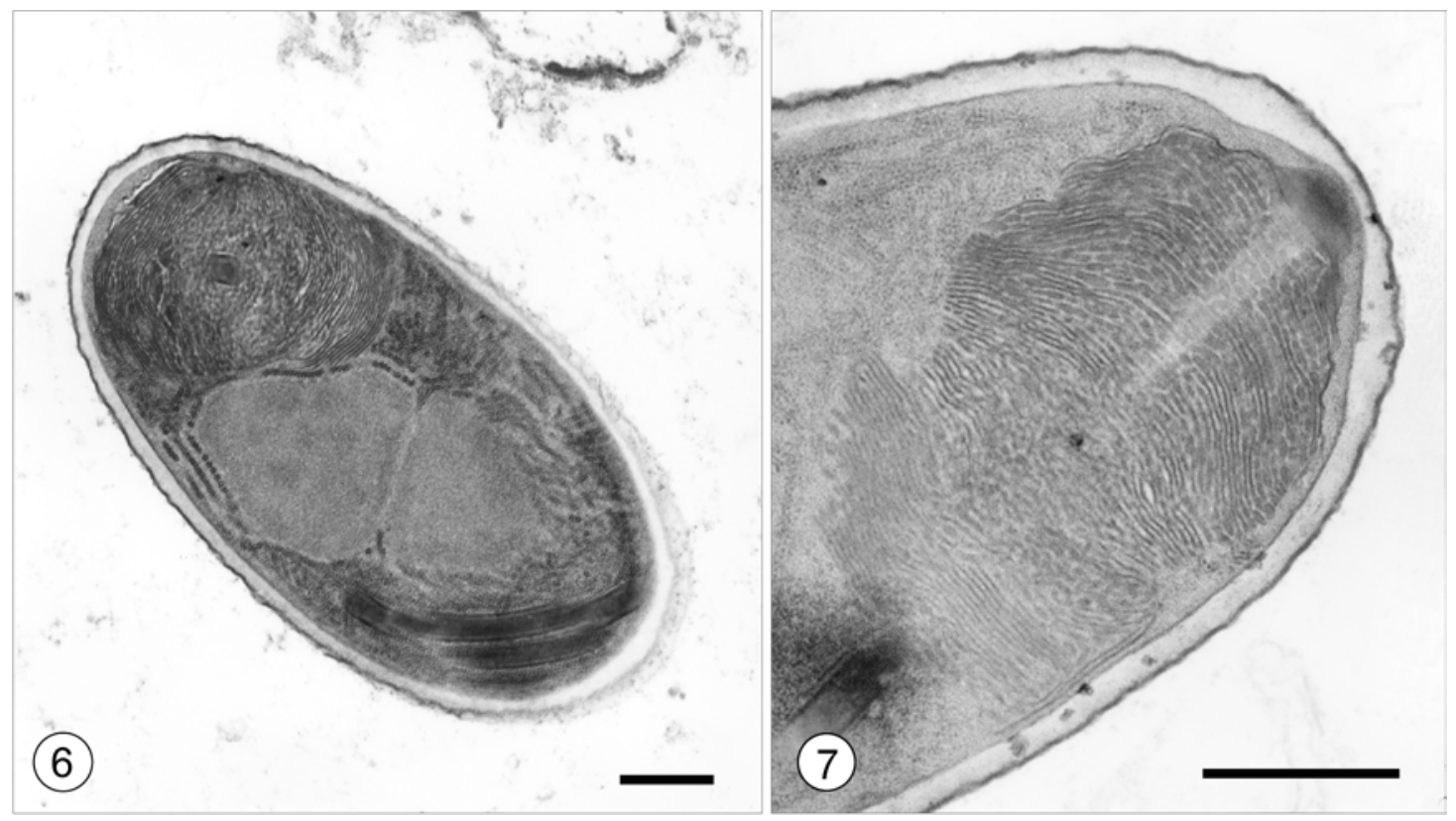

Figs. 6, 7. Amblyospora ferocis. Developmental stages in ovaries of adult Psorophora ferox. TEM. Fig. 6. Binucleate spore. Fig. 7. Enlargement of polaroplast. Scale bars: Figs. $6,7=0.5 \mu \mathrm{m}$.

ovaries of adult $P$. ferox are similar in morphology and ultrastructural features to other species of Amblyospora (Andreadis and Hall 1979, Andreadis 1985a, 1988, Hall and Washino 1986, Sweeney et al. 1988, Becnel 1992).

The reproductive capacity of $P$. ferox infected with $A$. ferocis decreased significantly in two analysed parameters, fecundity and egg hatch. A significant reduction $(\mathrm{p}<$ 0.0001 ) of $42 \%$ was observed in the average number of eggs laid by infected females when compared with healthy females. A decline in egg hatch was also observed with eggs produced by infected females. Forty-three percent fewer eggs were produced by infected females compared with healthy females. This indicates a negative impact of A. ferocis on the reproductive capacity of $P$. ferox. This differed from females of Culex salinarius infected with Amblyospora salinaria Becnel et Andreadis, 1998 where there were no significant differences found in the overall fecundity of infected females but a significant reduction of $52 \%$ in egg hatch (Andreadis and Hall 1979). Edhazardia aedis (Kudo, 1930) has been reported to reduce both fecundity and egg hatch in Aedes aegypti. The overall reduction in fecundity for $A$. aegypti infected with $E$. aedis was $69 \%$ with egg hatch reduced by $20 \%$ (Becnel et al. 1995). The causes for reduction in fertility and egg hatch may be related to the destruction of the ovaries and with the decrease of the nutritious reserves for the parasite (Gaugler and Brooks 1975, Brooks 1988).

There are numerous reports of inflammatory responses in insects to microsporidia (Brooks 1988). Melanized spores of Nosema stegomyiae have been reported only in adult Aedes aegypti (Marchoux et al. 1903) while melanized spores of Brachiola algerae have been found in both larvae and adults of Anopheles stephensi and A. aegypti (Vávra and Undeen 1970). This reaction appears to be primarily associated with cellular activities of haemocytes that phagocytize and encapsulate microsporidian spores released into the haemolymph to form nodular cysts that are melanized. The detrimental effects of this host response on the viability of spores are unknown.

During the survey period we observed that larvae infected with $A$. ferocis appeared when the first brood of mosquitoes hatched at the beginning of the season (October). This would indicate that these infected larvae come from diapausing eggs of infected females laid in the previous season (April-May). Infection rates in larvae were low during the spring and summer with a large increase in infection during the autumn (March and April). This pattern of infection is similar to that observed for Amblyospora connecticus in Ochlerotatus cantator where the autumn epizootics coincide with the appearance of the intermediate copepod host Acanthocyclops vernalis (Andreadis 1990). The death of large numbers of infected mosquito larvae results in the release of meiospores that infect the copepod host. Amblyospora connecticus over winters in the copepod host and development is arrested until spring. At that time, the copepods die, releasing spores that horizontally infect newly hatched larval $O$. cantator. The resulting infected adult females develop a benign infection with the formation of binucleate spores and subsequently lay infected eggs throughout the summer. The prevalence data for adult $P$. ferox infected with $A$. ferocis similarly fits this pattern with infected adults occurring throughout the summer. However, we did 
not find evidence for an infected intermediate host in early spring or during the autumn epizootic as occurs in $A$. connecticus (Andreadis 1990) and our laboratory transmission experiments were also not successful. The intermediate host for A. connecticus occurs only during the spring and autumn and aestivates for most of the summer and winter. It is possible that we began sampling after the infected copepods died in the spring and that they occur only during short periods in both the spring and autumn.

\section{REFERENCES}

ANDREADIS T.G. 1985a: Life cycle, epizootiology, and horizontal transmission of Amblyospora (Microspora: Amblyosporidae) in a univoltine mosquito, Aedes stimulans. J. Invertebr. Pathol. 46: 31-46.

ANDREADIS T.G. 1985b: Experimental transmission of a microsporidian pathogen from mosquitoes to an alternate copepod host. Proc. Natl. Acad. Sci. USA 82: 5574-5577.

ANDREADIS T.G. 1988: Amblyospora connecticus sp.nov. (Microsporida: Amblyosporidae): horizontal transmission studies in the mosquito, Aedes cantator and formal description. J. Invertebr. Pathol. 52: 90-101.

ANDREADIS T.G. 1990: Epizootiology of Amblyospora connecticus (Microsporida) in field populations of the saltmarsh mosquito, Aedes cantator, and the cyclopoid copepod, Acanthocyclops vernalis. J. Protozool. 37: 174-182.

ANDREADIS T.G., HALL D.W. 1979: Development, ultrastructure, and mode of transmission of Amblyospora sp. (Microspora) in the mosquito. J. Protozool. 26: 444-452.

BECNEL J.J. 1992: Horizontal transmission and subsequent development of Amblyospora californica (Microsporida: Amblyosporidae) in the intermediate and definitive hosts. Dis. Aquat. Org. 13: 17-28.

BECNEL J.J., GARCÍA J.J., JOHNSON M. 1995: Edhazardia aedis (Microspora: Culicosporidae) effects on the reproductive capacity of Aedes aegypti (Diptera: Culicidae). J. Med. Entomol. 32: 549-553.

BROOKS W.M. 1988: Entomogenous Protozoa. In: C.M. Ignoffo and N.B. Mandava (Eds.), CRC Handbook of Natural Pesticides. Vol. V. Microbial Insecticides, Part A, Entomogenous Protozoa and Fungi. CRC, Boca Raton, pp. $1-149$.

DARSIE R.F., MITCHELL C.J. 1985: The mosquitoes of Argentina. Parts I and II. Mosq. Syst. 17: 163-334.

DUSSART B.H. 1969: Les Copépodes des Eaux Continentales d'Europe Occidentale. Vol. 2. Cyclopoides et Biologie. Boubeé et Cie., Paris, 292 pp.

FORATTINI O.P. 1965: Entomología Médica, Vol. 2. Culicini: Culex, Aedes e Psorophora. Universidade de São Paulo Press, São Paulo, 506 pp.

GARCÍA J.J. 1989: Primer registro de microsporidiosis en culícidos (Diptera: Culicidae) de la República Argentina. Rev. Soc. Entomol. Argent. 47: 100-108.

GARCÍA J.J., BECNEL J.J. 1994: Eight new species of microsporidia (Microspora) from Argentine culicids (Diptera: Culicidae). J. Invertebr. Pathol. 64: 243-252.
GAUGLER R.R., BROOKS W.M. 1975: Sublethal effects of infection by Nosema heliothidis in the corn earworm, Heliothis zea. J. Invertebr. Pathol. 26: 57-63.

HALL D.W., WASHINO R.K 1986: Sporulation of Amblyospora californica (Microspora: Amblyosporidae) in autogenous female Culex tarsalis. J. Invertebr. Pathol. 47: 214 218.

LANE J. 1953: Neotropical Culicidae I and II. University of São Paulo Press, São Paulo, 548 pp.

MARCHOUX E., SALIMBENI A., SIMOND P.L. 1903: La fievre jaune. Rapport de la mission francaise. Ann. Inst. Pasteur 17: 665-731.

MICIELI M.V., GARCÍA J.J., BECNEL J.J. 1998: Horizontal transmission of Amblyospora dolosi (Microsporidia: Amblyosporidae) to the copepod Metacyclops mendocinus. J. Invertebr. Pathol. 72: 330-335.

MICIELI M.V., GARCÍA J.J., BECNEL J.J. 2000a: Horizontal transmission of Amblyospora albifasciati García and Becnel, 1994 (Microsporidia: Amblyosporidae), to a copepod intermediate host and the neotropical mosquito Aedes albifasciatus (Macquart, 1837). J. Invertebr. Pathol. 75: 76-83.

MICIELI M.V., GARCÍA J.J., BECNEL J.J. 2000b: Life cycle and description of Amblyospora camposi n. sp. (Microsporidia: Amblyosporidae) in the mosquito Culex renatoi (Diptera, Culicidae) and the copepod Paracyclops fimbriatus fimbriatus (Copepoda, Cyclopidae). J. Eukaryot. Microbiol. 47: 575-580.

REID J.W. 1985: Clave de identificao e lista de referencias bibliográficas para as espécies continentais sudamericanas de vida livre da ordem cyclopoida (Crustacea, Copepoda). Bol. Zool., Univ. São Paulo 9: 17-143.

RINGUELET R.A. 1958: Los crustáceos copépodos de las aguas continentales de la República Argentina. Sinopsis sistemática. Contrib. Cient. Fac. Cienc. Exact. Fís. Nat. Univ. B. Aires, Zool. 1: 35-126.

SWEENEY A.W., GRAHAM M.F., HAZARD E.I. 1988: Life cycle of Amblyospora dyxenoides sp. nov. in the mosquito Culex annulirostris and the copepod Mesocyclops albicans. J. Invertebr. Pathol. 51: 46-57.

SWEENEY A.W., HAZARD E.I., GRAHAM M.F. 1985: Intermediate host for an Amblyospora sp. (Microspora) infecting the mosquito, Culex annulirostris. J. Invertebr. Pathol. 46: 98-102.

VÁVRA J., UNDEEN A.H. 1970: Nosema algerae n. sp. (Cnidospora, Microsporida) a pathogen in a laboratory colony of Anopheles stephensi Liston (Diptera: Culicidae). J. Protozool. 17: 240-249. 